\title{
O PAPEL DO MEIO AMBIENTE NA POLÍTICA EXTERNA BRASILEIRA
}

\author{
Joana Carlos Bezerra*
}

\begin{abstract}
Resumo
O objetivo deste artigo é analisar o papel do meio ambiente na política externa brasileira, com foco na Amazônia, a partir da análise de textos e documentos estratégicos. O exame desse material permite concluir que a floresta tropical sulamericana, apesar de estar presente na política externa do Brasil desde os tempos coloniais, aparece fundamentalmente, até os dias de hoje, pelas lentes de soberania e segurança nacional, e não numa perspectiva ambiental estratégica.

Palavras-chave: Amazônia; política ambiental; política externa; Brasil.
\end{abstract}

\begin{abstract}
The aim of this article is analyse the role of the environment in the Brazilian foreign policy, with a special focus in the Amazon rainforest, using as basis for this analysis a bibliographical research. A thorough examination leads to the conclusion that the South American rainforest has been part of the Brazilian foreign policy since colonial times but it appears, fundamentally until today, under the auspices of sovereignty and national security, rather than with an environmental strategic perspective.

Keywords: Amazon; environmental policy; foreign policy; Brazil.
\end{abstract}

\section{Introdução}

A dimensão política da questão ambiental já não é mais questionada. Com o surgimento da agenda ambiental internacional em 1970, os países que ainda não possuíam uma

\footnotetext{
* Graduada em Política e Relações Internacionais (Sussex), Mestre em Environment, Development and Policy (Sussex) e Doutora em Ambiente e Sociedade (UNICAMP). E-mail: jcbezerra@hotmail.com.
} 
política externa voltada para o meio ambiente tiveram que definir suas posições. O Brasil não foi exceção.

O objetivo deste trabalho é ressaltar três características inerentes à política externa brasileira voltada para o meio ambiente, em particular para a floresta sul-americana, a partir do surgimento da agenda ambiental internacional na década de 1970. Primeiro, a Amazônia tem sido tratada como uma questão de segurança e soberania. Como consequência, não se tem levado em consideração adequadamente a conservação de seus recursos. Segundo, a política externa, desde o surgimento da agenda ambiental internacional, tem tido o desenvolvimento nacional como fio condutor. Em terceiro lugar a política externa brasileira mantém até os dias de hoje as idéias centrais que a dirigem desde a década de 1970 .

O trabalho é dividido em seis partes. A primeira aborda o papel da Amazônia na política externa do Brasil até o início da agenda ambiental internacional em 1972, com a Conferência de Estocolmo. As quatro seções seguintes se referem à política externa brasileira em relação ao meio ambiente nas décadas de 1970, 1980, 1990 e 2000. A última seção apresenta as considerações finais.

A pesquisa que serviu de base para a elaboração deste artigo pode ser dividida em três partes. A primeira é uma pesquisa histórica sobre a Amazônia e o meio ambiente na política externa brasileira, focando na década de 1970 em diante. A segunda parte é uma análise das informações levantadas, tanto em relação às Conferências das Nações Unidas sobre o Meio Ambiente em 1972 e 1992, quanto em relação à posição do Brasil na Conferência. A terceira parte é focada no levantamento de informações e análise de eventos contemporâneos, ênfase na política do governo brasileiro em relação à Amazônia do ano 2000 em diante. A pesquisa é descritiva, explanatória e exploratória. Ela é descritiva porque aborda a política de expansão de território por parte de Portugal quando o Brasil era uma colônia e já na República, assim como as Conferências das Nações Unidas de 1972 e 1992 e a posição do Brasil em relação ao meio ambiente entre as Conferências. É explanatória porque o que foi encontrado 
na parte descritiva da pesquisa é analisado. A pesquisa é exploratória porque aborda a continuação da posição do Brasil em relação ao meio ambiente.

\section{Amazônia antes da Política Ambiental internacional}

Desde que o Brasil era colônia, a floresta ocupou um lugar na política externa do país. Esta participação contínua se deveu mais a questões de segurança e soberania do que a questões ligadas à sua biodiversidade.

A Amazônia, floresta tropical na América do Sul que se estende por nove países (Brasil, Bolívia, Colômbia, Equador, Guiana, Guiana Francesa, Peru, Suriname, Venezuela), é o lugar mais biodiverso do mundo. A floresta representa $1 / 20$ da superfície do planeta Terra (Viana, 2001) e é o habitat de cerca de 1,8 milhão de espécies diferentes de plantas e animais (Becker; Stenner, 2008). É na Amazônia que se localizam as principais bacias hidrográficas do planeta (Faleiro, 2001), com 17\% da água doce do mundo na região (Becker, 2004).

Desde os tempos em que o Brasil era colônia, a Amazônia já integrava o cenário político internacional. Isto se devia principalmente a dois fatores. O primeiro é histórico, já que a floresta foi alvo de disputas entre as colônias europeias entre os séculos XVI e XIX. O segundo fator é geográfico: a floresta sul-americana se encontra espalhada pelo território de nove países.

$\mathrm{Na}$ época colonial, a política externa voltada para a Amazônia era baseada na conquista de territórios, o que fazia parte do mote português de expansão do império. A Amazônia não fazia parte das regiões mais importantes do país. Suas características naturais dificultavam a ocupação territorial. A densidade populacional da região, assim como sua participação na história do país, foi inconstante por causa de dois fatores: a valorização de seus recursos, que funcionava em ciclos pouco duradouros, e a importância dada à região pelos centros que dominavam o cenário político e econômico internacional na época 
(Becker, 1982). Durante o período colonial, o Brasil, assim como ocorria com a América Latina e com os países do continente africano, era visto pelas potências europeias como uma fronteira de recursos. Ser uma fronteira de recursos significa que a região é uma zona de povoamento novo, ou seja, um território sem ocupação, com recursos naturais significativos. Essas fronteiras são distantes dos centros populacionais, o que sugere que no passado sua ocupação não foi considerada uma boa opção pelos altos custos envolvidos. A ocupação dessas fronteiras só se torna viável na medida em que seus recursos forem de alto valor (Friedmann apud Becker, 1982) ${ }^{1}$. Mesmo depois da independência, a maneira como o país era visto pelas potências continuou a mesma. A função do Brasil neste capítulo da história que durou até o início do século XX era fornecer matérias-primas para os centros da época, os países europeus.

Assim como o Brasil era visto como uma fronteira de recursos, a Amazônia era vista da mesma maneira pelos países que a constituíam. Os países da América do Sul viam a Amazônia como um lugar a ser explorado pelos seus recursos. A região funcionava como uma "ilha" econômica (Becker, 1982), cuja única função era prover matérias-primas locais para fora do país. O ciclo da borracha levou à região forças devastadoras no que diz respeito à extração dos recursos, o que produziu cenários econômicos e sociais de pouca equidade (Pádua, 2000). Com o fim do ciclo da borracha a região passou a ser vista como um "inferno verde", com solos pouco próprios e com rápida deterioração (Becker, 1982).

A percepção do papel da floresta na consolidação territorial do Brasil não ficou restrita apenas ao período colonial. Depois da proclamação da República, e durante todo o mandato de Rio Branco (1902-1912), a região continuou a desempenhar um papel importante em relação a este objetivo. A resolução da questão do

\footnotetext{
${ }^{1}$ A ocupação do território brasileiro foi focada em áreas de grande importância biológica a múltiplos usos (Ferreira, L. C., 2005).
} 
território do Amapá (1900), que envolvia a França, e a aquisição do Acre (1903), colocando um fim na disputa com a Bolívia, ilustram este último ponto.

O período entre o término da gestão do Rio Branco em 1912 e a década de 1960 é marcado pela aproximação com os Estados Unidos, que passam a ocupar o lugar que a Europa anteriormente tinha para o Brasil. Com este novo cenário e com o espaço territorial do país muito bem delimitado, a floresta sul-americana perde um pouco seu espaço na política externa brasileira. Soma-se a isso o fim do ciclo da borracha, que interrompeu bruscamente o fluxo de investimentos, o que teve um impacto na população da região (Pádua, 2000). Além disso, a bacia do Prata ocupava um papel de destaque na política externa na primeira metade do século XX, já que neste período a Argentina apresentava vantagens econômicas e militares em relação ao Brasil.

Apesar de perder espaço na agenda política, a floresta Amazônica manteve certa importância por duas razões. A primeira é o fato de a floresta se estender pelo Brasil e pelos países andinos - com exceção do Chile - o que era importante na disputa com a Argentina pela hegemonia na região. A segunda refere-se à possibilidade de usar a bacia Amazônica como um trampolim para a sua projeção na região. Somente entre os anos 1940 a 1970 é que se desenvolve o projeto de utilização da bacia Amazônica como uma questão estratégica.

A Amazônia retorna à pauta da política brasileira com mais força a partir de 1940, com o surgimento do projeto desenvolvimentista (Antiquera, 2006). O projeto reflete o entendimento da região como uma fronteira de recursos. A criação da Superintendência do Plano de Valorização Econômica da Amazônia (SPVEA), em 1953, marca o início das políticas públicas voltadas a uma maior integração da região à vida econômica do país. No cenário internacional destaca-se a proposta de criação do Instituto Internacional da Hiléia Amazônica (IIHA), que o Brasil levou à UNESCO em 1946. O insucesso do IIHA apagou, mais uma vez, a região da agenda da política externa brasileira. A floresta retorna à agenda com o golpe militar. 
Em contraste com esse movimento no âmbito externo, internamente, a partir de 1953 com a criação da SPVEA (Superintendência do Plano de Valorização Econômica da Amazônia), a Amazônia entra e se firma na agenda de políticas públicas. A proposta do estado era incorporar a floresta ao resto do Brasil. Algumas dessas iniciativas são o Plano de Metas de 1958, a criação da SUDAM (Superintendência do Desenvolvimento da Amazônia) em 1966, a criação da zona Franca de Manaus em 1967, o Programa de Integração Nacional em 1967, o INCRA e seu papel no segundo Plano Nacional de Desenvolvimento, entre outros (Antiquera, 2006). Todas essas iniciativas compõem o projeto desenvolvimentista do Brasil que nasceu na década de 1950.

A prioridade do governo Costa e Silva (1967-1969), que tinha como foco a segurança, passa a ser o desenvolvimento ${ }^{2}$. Por esse motivo, sua política externa foi chamada de "diplomacia da prosperidade". Em seu governo, Médici (1969-1974) tenta impor a visão do Brasil como potência, adotando assim uma postura mais individualista, se afastando de acordos multilaterais. Durante esse período, a Amazônia aparece de maneira pouco expressiva na política externa brasileira. Este papel da região refletia em parte a falta de consciência espacial do país, o que significa que o território como um todo não era usado no desenvolvimento da política externa (Antiquera, 2006).

A política externa reflete - pelo menos em parte - a política interna de um país. O Brasil é um ator que sempre participou na formulação e nas discussões sobre regimes ambientais. No entanto, no que se refere à implementação do que foi acordado, o país sempre deixou a desejar. Esta dificuldade de implementação nacional do que foi decidido na esfera internacional é o resultado

${ }^{2} \mathrm{O}$ desenvolvimento passou a ser prioridade do governo brasileiro a partir dos anos 1950. Durante os primeiros anos da ditadura militar este objetivo não foi esquecido, mas era não era o único e principal. Foi com Costa e Silva que o desenvolvimento voltou a ser absoluto na agenda. 
do impasse interno em relação à questão ambiental. Ao mesmo tempo em que é vista como empecilho ao desenvolvimento, a exuberante riqueza natural da região é também percebida como fonte de orgulho nacional. A floresta é, portanto, marcada por uma contradição nacional. Da década de 1950 em diante, por exemplo, a Amazônia foi o foco de políticas públicas incompatíveis entre si. Ao mesmo tempo em que fazia parte do modelo de desenvolvimento do país, também era o alvo de políticas do Ministério do Meio Ambiente, que tinham (têm) como o objetivo a conservação (Becker, 2004; Becker, 2007).

\section{Década de 1970}

A década de 1970 é extremamente importante no que se refere à questão ambiental por dois pontos. Primeiro, é neste período que surge a agenda ambiental internacional com a Conferência de Estocolmo e, segundo, a Amazônia aparece em destaque na política externa brasileira com a elaboração do Tratado de Cooperação Amazônica.

A Conferência das Nações Unidas sobre o Meio Ambiente Humano, realizada em Estocolmo, em 1972, é tida como o marco formal do início da agenda ambiental. No entanto, para entender a convocação da reunião é necessário voltar um pouco no tempo. Os impactos das atividades humanas se fizeram mais notórios no século $X X$, principalmente na sua segunda metade, como a smog londrina de 1952 e o acidente do navio Torrey Canyon em 1967.

No ano de 1968, depois da Conferência da Biosfera, ficou clara a necessidade de se organizar uma reunião de estados para discutir o controle da poluição do ar e a chuva ácida problemas presentes na realidade dos países industrializados (Ribeiro, 2001). Esta reunião foi a Conferência das Nações Unidas sobre o Meio Ambiente Humano e foi realizada em Estocolmo em 1972. A agenda da reunião focava as questões técnicas dos problemas ambientais. Compareceram 113 estados, e a presença deles implicou 
a inclusão da questão ambiental na agenda desses países. A Conferência foi marcada pela dicotomia entre a posição dos países do norte e a dos países do sul. Os países desenvolvidos defendiam a tese do crescimento zero, ou seja, interromper o crescimento econômico dos países em desenvolvimento já que este processo era poluidor e devorador de recursos naturais. Os países do sul defendiam o direito ao desenvolvimento. Nesta Conferência o Brasil liderou este último grupo de países. $\mathrm{O}$ único tema tratado pelo Brasil que não foi apoiado unanimemente pelos países do sul foi a discussão com a Argentina sobre Itaipu ${ }^{3}$.

A posição defendida pela delegação brasileira em Estocolmo pode ser definida em três pontos claros (Guimarães, 1991). Primeiro, o processo de desenvolvimento não poderia ser sacrificado por um meio ambiente mais limpo. Segundo, os países em desenvolvimento não deveriam pagar para reverter a degradação ambiental já que a responsabilidade pela degradação recaía sobre os países desenvolvidos. O fato de estes países serem também os portadores de tecnologias que poderiam auxiliar nesta "limpeza" era uma coincidência feliz. Terceiro, a soberania não deveria ser sacrificada por interesses ambientais. Os países desenvolvidos argumentavam que a exploração e a deterioração da natureza em um determinado país poderiam gerar impactos além de suas fronteiras. Esta possibilidade, que torna a questão ambiental global na sua essência, seria a base para o argumento de que algumas regiões do mundo deveriam ser monitoradas internacionalmente. Contra esta posição, os países em desenvolvimento defenderam fortemente o direito de explorar os recursos naturais dentro de suas fronteiras. Na posição do Brasil em 1972, o desenvolvimento aparece como prioridade acima de qualquer outra.

\footnotetext{
${ }^{3}$ Argentina e Brasil tinham diferentes opiniões sobre o aproveitamento hídrico da Bacia do Prata.
} 
Até o governo Geisel, a Amazônia ficou em segundo plano na política externa do país, diluída na questão geral ambiental. Foi nesse período (1974-1979) que o Tratado de Cooperação Amazônica (TCA) foi negociado e em seguida assinado. Com este Tratado, a Amazônia foi elevada ao primeiro plano da política externa brasileira. No cenário político internacional, o eixo lesteoeste foi minimizado ao mesmo tempo em que eixo norte-sul voltou a ser parte da política externa. Geisel retomou o paradigma da política externa brasileira da busca de autonomia no cenário internacional (Gonçalves; Miyamoto, 1993). O termo "pragmatismo responsável", marca registrada de Geisel, fundamentou a projeção do Brasil como um ator de peso no cenário internacional. Este termo engloba três fatores (Guimarães, 1991): compromisso com países desenvolvidos, apoio ativo às causas dos países do terceiro mundo, e uma forte aversão a alinhamentos automáticos.

$\mathrm{O}$ fato de a Amazônia aparecer em segundo plano, no entanto, não significava que preocupações com região fossem inexistentes. A integridade territorial do País, a questão da soberania na floresta, a necessidade de ter um contraponto em relação à influência dos argentinos nos países na America do Sul e de firmar a influência do país na região sul-americana, eram preocupações recorrentes (Antiquera, 2006). Apesar de a Amazônia só ganhar o primeiro plano da política com Geisel, a partir do golpe de 1964 a região foi ganhando paulatinamente espaço. Já em 1966 foi apresentada a Operação Amazônia, que teve como principais resultados, ambos no âmbito interno, duas mudanças: a do SPVEA para a SUDAM (Superintendência para o Desenvolvimento da Amazônia) e a do Banco de Crédito da Amazônia para o BASA, Banco da Amazônia.

Apesar de não estar ausente na política externa brasileira, foi apenas no final da década de 1970 que a Amazônia ganhou um lugar de destaque com a elaboração do TCA. Quatro fatores contribuíram para isso (Antiquera, 2006). Primeiro, o pragmatismo responsável, que deu suporte ao Tratado. Segundo, o desenvolvimento econômico atingido pelo país, que 
facilitou a integração da Amazônia ao resto do Brasil. Terceiro, a assinatura do Pacto Andino, que impulsionou uma discussão de um Tratado que incluísse o Brasil. Quarto, a bipolaridade lesteoeste, que havia diminuído, abrindo espaço para outras questões começarem a aparecer nas discussões internacionais.

Na década de 1970 é definida a base da política ambiental brasileira, que, apesar das diferenças no contexto interno e externo, está presente até os dias de hoje nas discussões internacionais sobre meio ambiente. A primazia do desenvolvimento fica clara desde o início da década. Esta primazia até hoje não foi contestada. Também fica claro o lugar ocupado pela Amazônia, vista sob a luz dos conceitos de soberania.

\section{Década de 1980}

A crescente importância que o tema ambiental passa a receber a partir de 1970 ultrapassa a barreira dos anos. Na década de 1980 o país sofre pressões internacionais e adota uma postura defensiva em relação à questão ambiental. Esta seção aborda as transformações corridas nos anos de 1980 a 1989.

O governo Figueiredo (1979-1985) mantém o pragmatismo responsável como um pilar da política externa do Brasil, agora com o nome de universalismo e com uma aproximação maior aos países do terceiro mundo (Ferreira, T., 2006). Os primeiros anos do TCA não são muito significativos, uma vez que a maior preocupação do Brasil em relação aos países que assinaram o Tratado se refere à segurança e a recursos naturais e energéticos, temas que não fazem parte do Tratado.

José Sarney chega à presidência em 1985. Depois de uma breve mudança nas diretrizes da política externa do Brasil com o chanceler Olavo Setúbal, o governo volta a manter as mesmas linhas da política externa que o governo anterior com Abreu Sodré à frente do Ministério das Relações Exteriores (Antiquera, 2006). É no final dessa década que a Amazônia ganha repercussão mundial, o que ocorreu basicamente por dois motivos. Primeiro, 
as queimadas na floresta chamaram a atenção da comunidade internacional. Imagens da floresta devastada rodaram o mundo. Nas discussões suscitadas por esta época também envolviam os diretos das populações indígenas. $\mathrm{O}$ segundo motivo foi o assassinato de Chico Mendes em 1988. O líder extrativista era conhecido mundialmente pelo seu trabalho e sua morte reforçou a ideia de que o Brasil não era capaz de cuidar da floresta. É nesta década que o país é rotulado o grande vilão do meio ambiente.

É no final da década que o Brasil adota uma postura defensiva em relação à questão ambiental. E é de acordo com essas linhas que é lançado o Programa Nossa Natureza em 1989. O programa é uma resposta direta à comunidade internacional, na tentativa de comprovar a capacidade brasileira de gerir seus recursos naturais. Os objetivos do Programa, que foram incluídos na Constituição, eram a proteção dos grandes complexos ecossistêmicos do país, a organização de forma sistemática da proteção do meio ambiente, entre outros (Kohlhepp, 1992). O programa desencadeou mudanças na política burocrática no setor ambiental no Brasil (Galvão, 1996). Cabe ressaltar que o Programa Nossa Natureza foi elaborado e monitorado pela Secretaria de Defesa Nacional, o que demonstra como a Amazônia era tratada como uma questão de segurança nacional (Canizio, 1991).

De acordo com o Brasil, o interesse nacional e a soberania na Amazônia brasileira estavam em jogo. Discutia-se internacionalmente a capacidade do Brasil de gerir a floresta e circulavam propostas de que a floresta era patrimônio da humanidade e a representação da Amazônia como pulmão do mundo. Para o Brasil estes entendimentos eram a base para novas formas de intervenção, que usavam a questão ecológica como abertura, mas que por trás guardavam outros interesses. A autodeterminação do Brasil estava sempre presente nos discursos de Sarney sobre o Programa e sobre a Amazônia. A questão amazônica abria a possibilidade de um grupo de estados impor seus interesses sobre outros estados. A elaboração do Programa Nossa Natureza foi uma resposta direta a isso. O modo 
como a Amazônia foi abordada internamente no final da década de 1980 evidencia forte ligação entre a floresta e os conceitos de soberania e segurança nacional.

\section{Década de 1990}

A nova década veio com mudanças. No cenário internacional chega ao fim da dicotomia capitalismo-socialismo. Neste novo cenário, três fatores são importantes (Cervo; Bueno, 2008): a supremacia da ideologia neoliberal, a primazia do mercado e a hegemonia militar norte-americana. O fenômeno da globalização, gerando rapidez e grande quantidade de transações comerciais, ditou uma nova realidade econômica. O Brasil não se adaptou facilmente a este novo contexto. Cinco ministros ficaram à frente do Ministério das Relações Exteriores entre os anos de 1990 e 1995. De 1995 a 2000, Luiz Felipe Lampréia assumiu o cargo, numa tentativa de gerar uma coerência na política externa brasileira.

A chegada de Collor ao poder coincide com o início da organização da Conferência das Nações Unidas sobre Meio Ambiente e Desenvolvimento no Rio de Janeiro em 1992. Fernando Collor de Mello assumiu a presidência do Brasil com a temática ambiental - com destaque para a Amazônia - já consolidada na agenda ambiental internacional.

No início do governo Collor permanece intacta a desconfiança da comunidade internacional em relação ao Brasil. A pressão em relação à postura ambiental do governo não era apenas externa. Internamente vozes também marcavam suas preocupações, como Listz Vieira, Fernando Gabeira e Fábio Feldman (Canizio, 1991). Como resposta, Collor nomeou José Lutzemberger, ecologista conhecido mundialmente por seu trabalho, como secretário nacional do meio ambiente, surpreendendo todos (Ferreira, 2003).

A realidade internacional era diferente da de 1972 e o país tinha uma imagem negativa a sanar. Levando isso em conta, 
algumas medidas foram tomadas, entre eles a nomeação de Lutzemberger como secretário, a reforma do sistema interno de meio ambiente como uma resposta institucional às pressões externas (Viola, 1999). Em abril de 1990, o Chanceler Francisco Rezek anunciou que o Brasil mudaria a sua postura externa em relação à ecologia (Canizio, 1991).

A inclusão do desenvolvimento na pauta da Rio-92 foi uma vitória da diplomacia brasileira. A junção entre desenvolvimento e meio ambiente refletia o desejo dos países em desenvolvimento. O país afirmava, desde as reuniões preparatórias, que os problemas ambientais dos países em desenvolvimento são decorrentes da falta de desenvolvimento econômico e social. Um tema, portanto, não poderia ser discutido sem o outro. Este argumento também havia sido apresentado em Estocolmo. A inserção do desenvolvimento como um dos temas principais da Conferência, e como imprescindível para a conservação do meio ambiente, representa uma não aceitação do congelamento das estruturas mundiais da época, extremamente desigual e desfavorável aos países do terceiro mundo (Canizio, 1991). A responsabilidade histórica dos países desenvolvidos também foi reforçada (Viola, 1999). Se olharmos atentamente para os três pontos que definem a posição do Brasil na Conferência em Estocolmo - o desenvolvimento não deveria ser sacrificado, os países desenvolvidos deveriam pagar pela despoluição do meio ambiente, a soberania não deve ser contestada - vemos que estes argumentos também marcaram presença na Rio-92.

O conceito de soberania, amplamente debatido em Estocolmo e, no caso do Brasil, também no final da década de 1980, também entrou na pauta da Rio-92. Não foi a revisão do conceito que foi discutida, mas a afirmação de sua importância como um conceito central. O exercício da soberania de um estado não estava em oposição à necessidade de conservação ambiental. Apesar de estimular a cooperação entre os estados no discurso, a soberania nacional sobre os recursos era sempre ressaltada.

O Brasil precisava de uma nova imagem internacional, e era responsabilidade da diplomacia torná-la real. A junção 
da questão ambiental com o desenvolvimento fez com que a ecologia não fosse usada como bandeira para outros fins que não a conservação dos recursos naturais. Na década de 1990, assim como na Conferência, as discussões sobre desenvolvimento giraram em torno do conceito de desenvolvimento sustentável. No entanto, isto não significa que o conceito tinha sido amplamente debatido e entendido por todos os atores e de fato posto em prática. A postura brasileira em relação à temática ambiental na década em questão fez com que o Brasil saísse do lugar de vilão (Canizio, 1991).

A diplomacia brasileira consagrou neste período três êxitos (Cervo; Bueno, 2008). O primeiro foi a realização da Conferência da ONU no Rio de Janeiro em 1992, o segundo foi a inserção do tema desenvolvimento no debate sobre meio ambiente, e o terceiro foi a superação da dicotomia norte-sul no cenário internacional e o estabelecimento de um clima de cooperação. As consequências da mudança de enfoque são vistas no resultado da Rio-92, entre eles a Convenção Quadro sobre Mudanças Climáticas, a Convenção sobre Diversidade Biológica e a Agenda 21.

Uma análise mais minuciosa nos permite perceber que, apesar de não se prender às "questões de princípio" e à postura defensiva do governo Sarney, a posição do governo Collor ainda mantém a mesma linha do governo anterior (Canizio, 1991), ou seja, reativa, apenas respondendo às críticas da comunidade internacional. Em sua essência, a postura brasileira ainda era a mesma, com suas raízes na década de 1970.

As ideias que circularam na década de 1980 sobre a Amazônia como pulmão do mundo e patrimônio da humanidade, vistas pelo Brasil como uma ameaça, foram combatidas pela diplomacia brasileira na década 1990. A falta de pesquisa sobre a Amazônia, presente desde a época da elaboração do TCA, não foi sanada. Com isso, a Convenção de Diversidade Biológica era violada com patentes de produtos amazônicos sendo registrados fora do País. Como resposta a esse cenário, que provocava discussões sobre soberania, o Congresso Brasileiro aprovou a Lei sobre Biossegurança (1995), a Lei de Patentes (1996), 
e a Lei de Cultivares (1997) (Cervo; Bueno, 2008). Também surgiram iniciativas internacionais, como o Programa Piloto de Proteção das Florestas do Brasil, que envolve Brasil, o Banco Mundial, a União Europeia e o G7. O estabelecimento do conceito de desenvolvimento sustentável como grande tópico da Conferência também ajudou a afastar as ameaças internacionais a Amazônia.

Depois de Collor e de Itamar Franco, foi a vez de Fernando Henrique assumir o governo brasileiro. O governo FHC adotou o planejamento territorial como política de governo. Esta posição se traduziu nos planos plurianuais: "Brasil em Ação" de 1996 a 1999, correspondente ao primeiro mandato de FHC, e "Avança Brasil" (PAB) de 2000 a 2003. Este último dividiu o Brasil em Eixos de Integração e Desenvolvimento (ENID), que são recortes verticais, para sua elaboração e implementação. No entanto, essa divisão não levou em consideração as diferenças populacionais, ecológicas e econômicas das regiões. Os programas refletem a prioridade do governo - o desenvolvimento - e os dois tiveram um grande impacto na Amazônia. Por isso, cabe destacar os principais pontos dos planos.

O primeiro programa foi lançado em agosto de 1996 e tinha como objetivo implementar " 42 empreendimentos estratégicos para o desenvolvimento sustentável" ${ }^{4}$. Com um custo total de R\$ 54 bilhões ${ }^{5}$, o programa foi criado para suprir a falta de investimentos que alavancariam o desenvolvimento do país, focando principalmente na infraestrutura e no desenvolvimento social. Um dos objetivos era a construção de vias de escoamento da produção dos cerrados (Carvalho, 1999).

O Programa "Avança Brasil" (PAB), lançado no ano 2000, segue as linhas do programa antecessor. O PAB representaria

${ }^{4}$ Programa Brasil em Ação. Disponível em: <www.abrasil.com.br>. 28 fev. 2009.

${ }^{5}$ Disponível em: <http://www.terra.com.br/istoe/politica/145532.htm>. 27 jan. 2009. 
um investimento de US\$ 43 bilhões entre 2000 e 2007, dos quais US\$ 20 bilhões seriam designados para infraestrutura, o que teria um impacto considerável no meio ambiente (Fearnside; Laurence, 2002; Fearnside, 2001). O objetivo do Plano era inserir o país como competidor na arena internacional, tendo, portanto, a exportação como um grande foco.

A Amazônia tinha um papel de destaque no PAB, sendo um de seus eixos. O objetivo das obras na região era baixar o valor do frete da produção de grãos, principalmente da soja, que era produzida no centro-oeste para a exportação. O Plano beneficiaria produtores e as hidroelétricas, também previstas, beneficiariam a indústria de alumínio. Ou seja, com a exportação e o investimento como principais focos do programa, os atores que se beneficiaram com o PAB foram os grandes produtores (Becker, 2004).

Cabe ressaltar que o PAB não considerava a dimensão ambiental, que apenas aparecia como um "leque de oportunidades" (Becker, 2004), refletindo o lugar que o meio ambiente ocupou durante no governo. As propostas do PAB demonstraram que a região ainda era vista como uma fronteira de recursos, reforçando papel da floresta como um lugar a ser utilizado para auxiliar o desenvolvimento do Brasil.

Na década de 1990 o papel do desenvolvimento na política externa mais uma vez transparece. A posição do Brasil em Estocolmo reaparece na Rio-92. Antes e durante a Conferência do Rio, o Brasil estimulou a cooperação entre os países, o que foi um dos seus grandes êxitos. No entanto, isto não quis dizer que a soberania foi esquecida. Este conceito, principalmente em relação aos recursos naturais, foi discutido com o intuito de reforçá-lo.

\section{O novo século}

A política externa do novo século ainda é regida pelo governo FHC. A chegada de Lula ao poder em 2003, no entanto, 
traz mudanças, que alcançaram a política externa. Celso Amorim assume o Ministério das Relações Exteriores. A política externa de Lula busca inserir o país na arena internacional, diversificando os parceiros assim como as opções estratégicas (Vigevani; Cepaluni, 2007). A estratégia de Lula, que é caracterizada pela adesão aos princípios e normas internacionais por meio de alianças entre países do sul e pela ampliação de acordos com parceiros não tradicionais, como a China e a Europa Oriental, tem sido chamada de "autonomia pela diversificação". Diretrizes do pragmatismo responsável de Geisel também estão presentes na política externa de Lula, como a afirmação de autonomia em relação às grandes potências e a ampliação das redes com os países do sul.

Na primeira edição da revista Diplomacia, Estratégia e Política (vol. 1, no 1, 2004), Amorim afirma que o elemento central da política externa do governo Lula tem a função principal servir de instrumento para apoiar o projeto de desenvolvimento econômico e social do Brasil (Amorim, 2004). Mais uma vez, num governo que se diz diferente dos antecessores, o desenvolvimento econômico aparece como fio condutor da política externa do Brasil.

A Conferência das Nações Unidas sobre o Desenvolvimento Sustentável em Joanesburgo em 2002 é a terceira grande Conferência sobre o tema. $\mathrm{O}$ foco da reunião era a Agenda 21, e o objetivo da Conferência era promover a incorporação de medidas concretas e o estabelecimento de metas para a sua implementação. Em Joanesburgo, assim como nas Conferências anteriores, o Brasil teve um papel de destaque, liderando a América Latina e Caribe nas negociações no período anterior ao encontro, quando foi elaborada a Iniciativa Latino-Americana e Caribenha para o Desenvolvimento Sustentável, que continha a Proposta Brasileira de Energia ${ }^{6}$, e durante a reunião. Mesmo sofrendo pressão por

\footnotetext{
${ }^{6}$ A Proposta Brasileira de Energia propunha que a região adotasse a meta de ter, até o ano de 2010,10\% de sua energia oriunda de fontes renováveis.
} 
causa da sua nova condição de grande poluidor de $\mathrm{CO}_{2}$ o Brasil continuou a defender a responsabilidade histórica das nações desenvolvidas.

Realizada logo após os acontecimentos em 2001 nos Estados Unidos que abalaram o mundo, a Conferência foi marcada por um clima de tensão. Ao invés de avançar, gastou-se muito tempo discutindo assuntos já tidos como certos, como o princípio da responsabilidade comum, porém diferenciada.

$\mathrm{Na}$ última década, principalmente depois do relatório do IPCC (Painel Intergovernamental sobre Mudanças Climáticas), em 2007, confirmando o papel das ações antrópicas nas mudanças climáticas, as discussões sobre o clima dominaram o debate ambiental. A Amazônia entra neste debate por conta do desmatamento e das discussões da REDD (redução de emissões por de degradação e desmatamento). As discussões sobre o desmatamento na floresta passaram a ser atravessadas pelas questões de soberania e de segurança. Nas discussões sobre o clima, assim como nas Conferências da ONU sobre meio ambiente, a posição do Brasil ecoou a posição de 1972. Isto ficou claro na última Conferência das Partes em Copenhague em 2009. Dilma Rousseff, a chefe da delegação brasileira na Conferência, por exemplo, cometeu o ato falho de dizer em uma entrevista que o meio ambiente é um empecilho ao desenvolvimento sustentável ${ }^{7}$.

Não é a primeira vez que durante Conferências das Partes da Convenção do Clima, enquanto o Brasil se esforça para passar uma imagem positiva e ativa em relação às mudanças climáticas, internamente projetos de lei com impacto negativo são votados. À mesma época da Conferência, enquanto o Brasil apresentava suas metas de redução de emissões - sem explicar como elas seriam atingidas - era discutido o projeto de lei no. 12 de 2003, que esvaziaria o IBAMA e seria um incentivo ao desmatamento e a degradação ${ }^{8}$. Na Conferência das Partes em Bali em dezembro de

${ }^{7}$ Disponível em: <http://wwww.oc.org.br/blog/?p=1065>. Acesso em: 28 dez. 2009. ${ }^{8}$ Jornal O Globo, 18 de dezembro de 2009, p. 39. 
2007, uma semana após anunciar a meta de redução de $40 \%$ do desmatamento irregular na Amazônia, o Presidente Lula concedeu anistia aos desmatadores por um ano, período em que o IBAMA não poderia aplicar multas?

\section{Continuidade ou mudança?}

Apesar de a Amazônia aparecer em alguns momentos da política externa do Brasil antes da década de 1970, é depois desta década que a região ganha mais destaque. Foi também na década de 1970 que se definiram as bases da posição brasileira para o meio ambiente, presentes até os dias de hoje. A década de 1980 é marcada por dificuldades internas com a crise da dívida e pela posição defensiva assumida pelo país em relação ao meio ambiente. Nesse período, mais do que no anterior, a floresta foi tratada sob a égide da soberania e da segurança nacional. Na década de 1990, o governo adota uma postura positiva em relação ao meio ambiente, mas mantém a essência reativa da década anterior. Na década de 2000, no governo Lula, apesar de embates internos entre os ministérios do meio ambiente e da agricultura, entre o ministério do meio ambiente a bancada ruralista, o desenvolvimento econômico aparece como ponto central.

A política externa do Brasil refletiu a prioridade dos seus governos. O desenvolvimento e a soberania foram, do período da ditadura militar até o governo Lula, os pontos que delinearam essa política.

Como vimos, a participação da Amazônia na política externa do Brasil não é fato recente. Desde os tempos em que o Brasil era colônia, a região já fazia parte da política externa voltada para a consolidação do território. Esta função foi além da época do

${ }^{9}$ Disponível em: <http://www.greenpeace.org/brasil/amazonia/noticias/ lula-cede-as-press-es-da-banca>. Acesso em: 29 dez. 2009. 
|170|

O Papel do Meio Ambiente na Política Externa Brasileira

Império, estando presente também no período em que Rio Branco esteve à frente do Ministério das Relações Exteriores. Dominavam, portanto, nesta época, os conceitos de segurança e soberania quando se tratava da floresta. Apesar de algumas diferenças, esta condição esteve presente de Rio Branco até os dias de hoje.

No cenário internacional atual, ganham força as discussões sobre mudanças climáticas e governança ambiental. A posição do Brasil sobre questões ambientais ainda ecoa a posição de 1972, apesar de diferenças claras, mesmo que no discurso, em algumas questões ${ }^{10}$. Naquela data, a lógica do crescimento econômico estava refletida na posição do Brasil em relação à questão ambiental e, portanto, também em relação à Amazônia. Isto no, fundo, não mudou. A política externa é influenciada pela política interna. Portanto, é preciso que esta última passe a ver a Amazônia como uma questão ambiental e uma questão estratégica, ou seja, levando em consideração suas singularidades e as possibilidades que delas decorrem. Um exemplo disso seria a valorização do vasto potencial genético da floresta, muito pouco explorado internamente e já muito cobiçado por atores externos. Outro exemplo seria a valorização dos serviços ambientais prestados pela floresta, passando pelo conhecimento das comunidades tradicionais da Amazônia. Estes dois casos exemplificam possibilidades de desenvolvimento econômico, se bem gerido, mais em sintonia com as particularidades locais, focado as questões ambientais e estratégicas. Muito menos nocivo do que a persistência em modelos falidos da década de 1970, que veem a floresta apenas como uma fronteira econômica.

\footnotetext{
${ }^{10}$ Refiro-me aqui ao discurso do Presidente Lula na COP-15, quando afirmou que o Brasil aceitaria que programas de mitigação com financiamento externo fossem submetidos a auditorias externas, o que tem implicações na discussão sobre soberania.
} 


\section{Bibliografia}

AMORIM, C. "Conceptos y Estrategias de la Diplomacia del Gobierno Lula". Revista de Diplomacia, Estratégia e Política. Brasília, v. 1, n. 1, p.41-48, 2004.

ANTIQUERA, D. A Amazônia e a Política Externa Brasileira: análise do tratado de cooperação amazônica e sua transformação em organização internacional (1978-2002). 2006. Dissertação (Mestrado) - Universidade Estadual de Campinas, Campinas.

BECKER, B.; STENNER, C. Um Futuro para a Amazônia. São Paulo: Oficina de Textos, 2008.

BECKER, B. "A Amazônia e a política ambiental brasileira". In: SANTOS, S.; BECKER, B. (Eds.) Território, territórios: ensaios sobre o ordenamento territorial. $3^{\text {a }}$ edição. Rio de Janeiro: Lamparina, 2007.

Amazônia: geopolítica na virada do III milênio. Rio de Janeiro: Garamound Universitaria, 2004.

. Geopolítica da Amazônia: a nova fronteira de recursos. Rio de Janeiro: Zahar Editores, 1982.

CANIZIO, M. O Brasil e a Questão Ambiental: um estudo de política externa brasileira. 1991. Dissertação (Mestrado) - Pontifícia Universidade Católica do Rio de Janeiro, Instituto de Relações Internacionais, Rio de Janeiro.

CARVAlHO, R. "A Amazônia rumo ao 'ciclo da soja'". Amazônia Papers 2. Amigos da Terra Programa Amazônia, 1999.

CERVO, A.; BUENO, C. História da Política Exterior do Brasil. $3^{\text {a }}$ Edição. Brasília: Editora Universidade de Brasília, 2008.

FALEIRO, A. "O desenvolvimento na Amazônia na visão dos produtores familiares rurais". In: VIANA, G.; SILVA, M.; DINIZ, N. (Orgs.). O desafio da sustentabilidade: um debate 
$|172|$

O Papel do Meio Ambiente na Política Externa Brasileira

socioambiental no Brasil. São Paulo: Fundação Perseu Abramo, 2001.

FEARNSIDE, P. “Avança Brasil: conseqüências ambientais e sociais na Amazônia". Cadernos da Fundação Adenhauer, São Paulo, v. 2, n. 4, p. 101-124, 2001.

FEARNSIDE, P.; LAURENCE, W. "O Futuro da Amazônia: os impactos do programa avança Brasil". Ciência Hoje. Maio de 2002.

FERREIRA, L. C. A questão ambiental: sustentabilidade e políticas públicas no Brasil. São Paulo: Boitempo, 2003.

FERREIRA, L. C. "Conflitos sociais e uso de recursos naturais: breves comentários sobre modelos teóricos e linhas de pesquisa". Política e Sociedade, n. 7, p. 105-118, 2005.

FERREIRA, T. "A Ruína do Consenso: a politica exterior no Brasil no periodo Figueiredo (1979-1985)". Revista Brasileira de Politica Internacional, Brasília, v. 49, n. 2, p. 119-136, 2006.

GALVÃO, L. D. Soberania, Natureza e Segurança Nacional: um estudo sobre a política externa brasileira para o meio ambiente. 1996. Dissertação (Mestrado) - Pontifícia Universidade Católica do Rio de Janeiro, Instituto de Relações Internacionais, Rio de Janeiro.

GONÇALVES, W.; MIYAMOTO, S. "Os Militares na Política Externa Brasileira: 1964-1984". Estudos Históricos, Rio de Janeiro, v. 6, n. 2, p. 211-246, 1993.

GUIMARÃES, R. The ecopolitics of development in the Third World: politics and environment in Brazil. Boulder/London: Lynne Rienner Publishers, 1991.

KOHLHEPP, G. “Desenvolvimento Regional Adaptado: o caso da Amazônia brasileira”. Estudos Avançados, v. 16, n. 6, 1992. 
PÁDUA, J. A. "Biosfera, história e conjuntura na análise da Questão Amazônica". História, Ciências, Sáude, v. VI, p. 793-811, 2000.

RIBEIRO, W. A ordem ambiental internacional. São Paulo: Contexto, 2001.

VIANA, G. "Impactos ambientais da política de globalização na Amazônia". In: VIANA, G.; SILVA, M.; DINIZ, N. (Orgs.). $O$ desafio da sustentabilidade: um debate socioambiental no Brasil. São Paulo: Fundação Perseu Abramo, 2001.

VIGEVANI, T.; CEPALUNI, G. "A política externa de Lula da Silva: a estratégia da autonomia pela diversificação". Contexto Internacional, v. 29, 2007.

VIOLA, E. A globalização da política ambiental no Brasil. 1999. Disponível em: <http://portaldomeioambiente.org.br/ editorias-editorias/terceiro-setor/ambientalismo/2021-aglobalizacao-da-politica-ambiental-no-brasil>. Acesso em: 20 mar. 2013.

\section{Websites}

Programa Brasil em Ação. Disponível em: <www.abrasil.com.br>. Acesso em: 28 fev. 2009.

$<$ http://www.terra.com.br/istoe/politica/145532.htm>. Acesso em: 27 jan. 2009.

<http://www.oc.org.br/blog/?p=1065>. Acesso em: 24 mar. 2013. $<$ http://www.greenpeace.org/brasil/amazonia/noticias/lula-cedeas-press-es-da-banca>. Acesso em: 24 mar. 2013. 